\title{
NEW CHALLENGES IN ABRASIVE WATER JET MACHINING
}

\author{
CATALINA CIOFU ${ }^{1 *}$, CATALIN TAMPU ${ }^{1}$, EUGEN HERGHELEGIU ${ }^{1}$, COSMIN \\ ALEXANDRU IANCU ${ }^{1}$, GHEORGHE BRABIE ${ }^{1}$
}

1 "Vasile Alecsandri” University of Bacau, Calea Marasesti 157, Bacau, 600115, Romania

\begin{abstract}
Abrasive water jet machining (AWJM) is one of the most important method used in cutting different types of materials: alloy sheet, marble, glass, rocks. This process is used in the aeronautic, automotive, metallurgy industries and even in some art techniques and textile industry. The method consists in transforming the kinetic energy of a solid particle directed with water jet at a high pressure to remove material through erosion and abrasion. AWJM is low cost equipment compared to other conventional cutting technologies. This paper is an attempt to review the achievements made in AWJM technology for different hardness materials.
\end{abstract}

Keywords: abrasive water jet machining, particle size, nozzle wear

\section{INTRODUCTION}

Abrasive water jet (AWJ) is of interest for different processes as: milling, turning, grinding, polishing and complex machining. Cutting of shapes from plate-type materials is the most frequent application by now for its very good standards of quality, but there is still a demand for improvement of AWJ machining (AWJM) [1, 2].

Some components with specific shape, size, load bearing capacity, geometrical and damage tolerance are made of composite materials to be light and strong, in order to withstand loads in difficult environments. Carbon fiber reinforced plastics are considered in aerospace, marine, robotics, construction, transportation, sporting goods, and defense applications for the material properties offering very high strength-to-weight ratio/high modulus-toweight ratio and corrosion resistance. The AWJM is a well-established non-conventional machining process which has proved to be effective in machining a wide range of materials including composites [3].

The tendency of using AWJM at micro scale in different industries demands optimization of process parameters and operation conditions. Some authors have recently concluded that the most important parameters that have a strong impact on the quality process are depth of cut, surface roughness, kerf characteristics and nozzle wear [2, $4,5,6]$. Other parameters considered for the process optimization which mainly affects the cutting precision are type of abrasive materials, abrasive flow rate, traverse speed, impact angle, interior nozzle diameter. A response for the machining process of the low hardness materials is the cryogenic assisted abrasive jet machining.

\section{OPTIMUM CONDITIONS FOR ABRASIVE WATER JET CUTTING QUALITY}

Researches made on AWJM agreed that the process does not induce any thermal defects and demonstrated that with optimal parameters it leads to delamination free trimming and milling of composite materials, with the possibility to control milling of depth surface [3,4]. Wire electric discharge (WED) and AWJ turning operation have been applied on hybrid metal matrix composites (MMC) to analyze surface roughness. Surface seemed to

\footnotetext{
* Corresponding author, email: catalina.ciofu@ub.ro

(C) 2019 Alma Mater Publishing House
} 
improve with more precisely finished when the rotational speed increased in WED turning operation. It was obtained a glossy finished surface in AWJ turning but slightly undulated and marked with several cutting traces of variable lengths and widths. When it was applied a lower rotation speed, traces were observed in large number both straight and curved oriented obliquely to the direction of jet flow. The surface porosity and voids from WED turned surfaces have been found due to the melting and vaporization of the matrix material. The surface porosity and voids from AWJ turned surfaces have been found due to impinging of high-speed abrasive along with the waterjet at the machined surface leading to plastic deformation and pulling of hard particles from the surfaces. Variation of microhardness and residual stresses were founded as tensile residual stresses in WED turning because of the thermal erosion process, but they become negligible when increasing the depth from the surface towards the core of the workpiece. In AWJ turning operation were founded compressive residual stresses due to pinning effect and no role of heat formation [7].

A shape distortion reduction method was considered for AWJ cutting depending on the declination angle and enables the limit traverse speed $v_{P \text { lim }}$ equation (1) to be calculated for a given material thickness. The theoretical basis comes from a model derived for limit cutting parameters [1].

$$
v_{P \lim }=\left[\frac{C_{A} S_{P} \pi d_{0} \sqrt{2 \rho_{j} p_{j}^{3} e^{-5 \xi_{j}^{L}}}\left(1-\alpha_{e}^{2}\right)}{8 H\left(p_{j} \rho_{j} \alpha_{e}^{2} e^{-2 \xi_{j} L}+\sigma \rho_{j}\right)}\right]-v_{P \min }
$$

where $C_{A}$ is the coefficient for adjusting jet power with respect to variations in abrasive content below and above the saturation level, $S_{P}$ is the coefficient of particle integrity (ratio of number of intact particles to total number of particles), $d_{0}$ is water jet diameter $(\mathrm{m}), \rho_{j}$ is the density of machined material $\left(\mathrm{kg} / \mathrm{m}^{3}\right), p_{j}$ is the pressure determined from density and speed of abrasive jet $(\mathrm{Pa}), H$ is the material thickness $(\mathrm{m}), \alpha_{e}$ is the coefficient of jet speed loss in the interaction process with the material, and $\sigma$ is the tensile strength (or compressive strength) of processed material $(\mathrm{Pa}), \xi_{j}$ is the coefficient of attenuation of abrasive jet between focusing tube outlet and material surface.

From the law of momentum conservation at the micro-level (grain of abrasive - grain of material) can be derived the coefficient $\alpha_{e}$ in equation (2) which determines the effectiveness of the disintegration process and its relation to selected material properties and several characteristics of the liquid jet.

$$
\alpha_{e}=1-\frac{\sqrt{2 p_{j}^{3}} K t}{\sqrt[8]{\rho_{j}} a_{m} \sigma}
$$

where $K$ is the material resistance to abrasive (e.g. hardness), $t$ is the interaction time (s), $a_{m}$ is the average size of material structural units $(\mathrm{m})$.

The traverse speed $v_{P Q}$ allows achieving the desired walls quality which is obtained from the basic relation and completed by the coefficient $C_{Q}$, equation (3).

$$
v_{P Q}=C_{Q} v_{p l i m}
$$

The jet delay causes deformations to workpiece (line segment BC in Figure 1) with a dependency of the declination angle on either traverse speed $v_{P \text { lim }}$ (alternatively $v_{P Q}$ ) or the material thickness.

Figure (1b) shows the position of the plane $\lambda$ when cutting a "column" sample using a tilted jet. The expected jet trajectory when penetrating the material is marked as a solid line and the expected deformation of the column sample after cutting is marked with a dotted line [1].

The declination angle is calculated at a selected traverse speed and is described by equation (4).

$$
\vartheta=\vartheta_{\lim }\left(\frac{v_{P}}{v_{P} \lim }\right)^{3 / 2}
$$

where $\vartheta_{\text {lim }}$ is the absolute value of angle determined at the depth $h_{\text {lim }}$ between the tangent to the striation curve and the jet axis at the point of impact $\left(^{\circ}\right)$. 
According to many experiments the optimum tilt angle was determined to be one half of the expected declination angle. When using the tilted jet, the plane $\lambda$ is required to be tangential to the circle described by the intersection of the jet axis and the workpiece surface at every point on the trajectory Figure (1b). Plane $\lambda$ is determined by the jet axis and the perpendicular to the workpiece surface at the point of jet impact. The diameters on the inlet $\left(D_{I}\right)$ and the outlet $\left(\mathrm{D}_{\mathrm{O}}\right)$ bases of "columns" cut from plane parallel material are included into Figure1 to compare parameters with each other and with respective results calculated from the presented theoretical base [1].

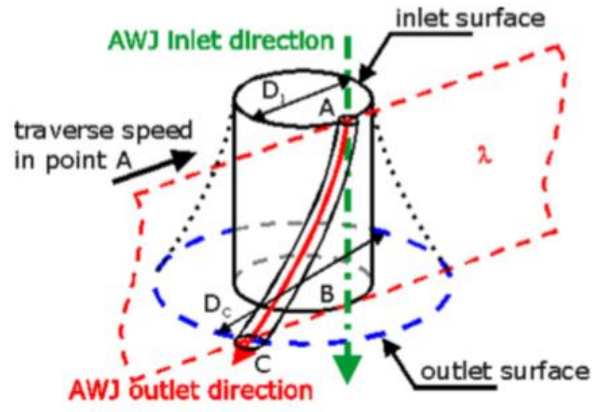

Fig. 1. (a) Column sample distortion [1].

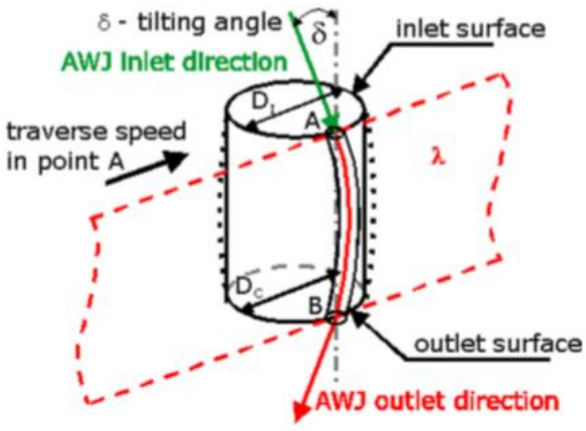

(a) (b)

An experimental method was applied for the investigation of the abrasive water jet cutting quality depending on the declination angle between the tangent to the striation and the impinging abrasive water jet axis. The declination angle was measured and used for the calculation of the required values of the material thickness, the traverse speed or the tilting angle of the cutting head. For the study it was used several materials: 10 types of Granite, Syenite, 10 types of Marble, Travertine, 3 types of Limestone, Slate, Sandstone R, 5 types of Steel, Glass, Plexiglass, Red plastic, Yellow plastic, Textite and Quarts glass. Declination angles were determined in the depth (equal to the material thickness) depending on the limit depths and limit angles. Assignment of the maximum values of the declination angles are considered for five zones of quality on the kerf walls. The maximum angles al located for the first four quality zones were assigned as $4^{\circ}, 10^{\circ}, 18^{\circ}$ and $32^{\circ}$ respectively. Authors concluded for the prediction and control of the cutting efficiency and quality that the database of materials with applicable characteristics could be easily prepared with the support of these parameters [8].

Static tensile and tension-tension fatigue tests have been conducted for studying the influence of damage induced by the AWJ milling process on the mechanical behavior on specimens with 4 different levels of machining quality. The static tensile and tension-tension fatigue tests methods were followed according to the ASTM standards D3039 and D3479 respectively. The differentiation in size (diameter) of micro and macro craters was determined by the interaction between abrasive laden waterjet and the workpiece. The diameter of microscopic craters (formed due to single abrasive particle impact) ranged between of $90 \mu \mathrm{m}$ and $200 \mu \mathrm{m}$ in SEM analysis. The craters created were close to the diameter range of garnet sand, 120 mesh size, which corresponds to a diameter of $125 \mu \mathrm{m}[3]$.

\section{PARTCILE VELOCITY DISTRIBUTION IN ABRASIVE JET MACHINING}

Ruslan M. and Fengzhou F. made a theoretical study on particle velocity in micro-abrasive jet machining and a two-dimensional axisymmetric numerical simulation to highlights the effects of nozzle diameter and length, air pressure, particle size and density on particle velocity development through the jet field. Velocity measurements consist in dividing air flow out of the nozzle into initial and main velocity regions. The velocity of air flow beyond the nozzle edge is preserved but, in the boundary, layers undergo deceleration because of the jet and ambient air mixing [9].

The mixing area becomes closer to the jet axis as the distance from the nozzle exit grows and forms a conical airfield (a potential core) with velocity equal to the air velocity at the nozzle diameter, $\mathrm{d}_{\mathrm{N}}$ (Figure 2). The potential core length $\mathrm{L}_{c}$ does not depend on air pressure or velocity but it is strictly connected to the nozzle 
diameter $\mathrm{d}_{\mathrm{N}}$, approximately 6.2 times the diameter of the nozzle for an air jet and around 100 times the diameter of the nozzle for a water jet [9].

It was concluded by the authors that the bigger the nozzle, the faster the particles. The laminar layer at the nozzle wall is approximately the same for all nozzles and an increase of the hydrodynamic diameter results in less loss of viscous friction. The averaged air velocity, pressure and density at the end of the nozzle are better preserved with larger diameters, which enable higher particle acceleration, even inside the nozzle (Figure 3).

The effects of nozzle diameter and length, air pressure, particle size and density are included in the equation (5) to determine the maximum particle velocity.

$$
v_{p \max }=547 d_{N}^{0.036} L_{N}^{0.03} d_{p}^{-0.06} \rho_{p}^{-0.06} P^{0.06}-530
$$

where $d_{N}, L_{N}, d_{p}$ are given in meters, $\rho_{p}$ is given in $\mathrm{kg} / \mathrm{m}^{3}$ and $\mathrm{P}$ is given in $\mathrm{hPa}$ [9]. The error of the predicted velocity does not exceed $10 \%$ for a wide range of operational conditions.

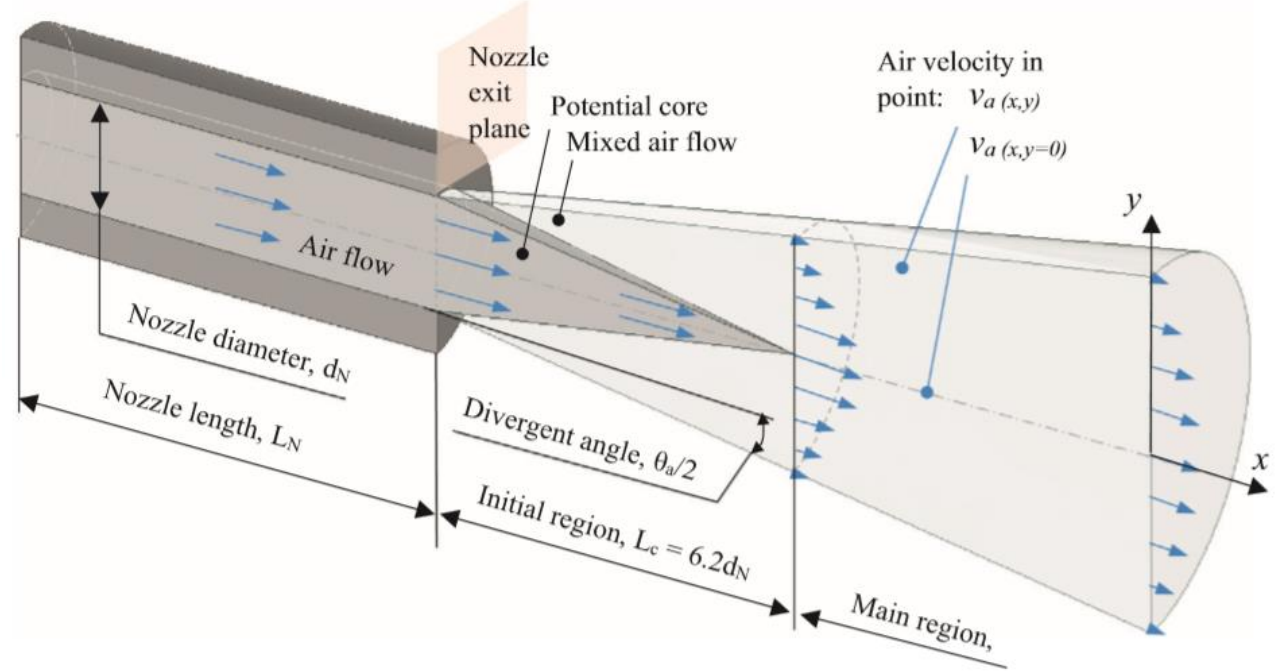

Fig. 2. Schema of air flow distribution [9].

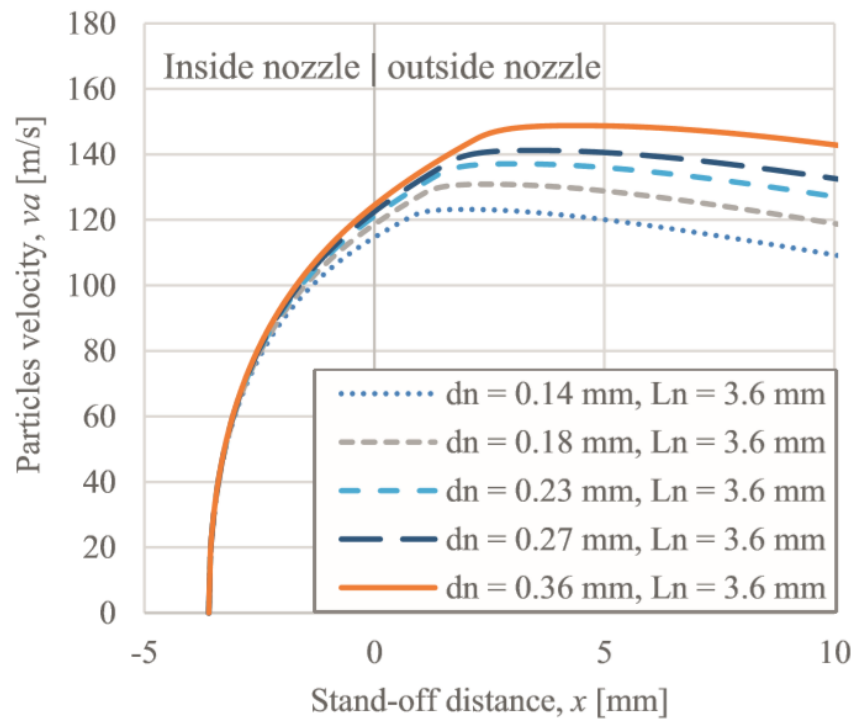

Fig. 3. Influence of nozzle diameter on particle centerline velocity $\left(d_{p}=10 \mu \mathrm{m}, \rho_{p}=3970 \mathrm{~kg} / \mathrm{m}^{3}, P=0.3 \mathrm{MPa}\right)[9]$.

Another study of particle velocity distribution at different pressures and standoff distances was made for both abrasive water jet (AWJ) and high-pressure abrasive slurry jet (HASJ). The impact crater densities at different 
angular locations within the impact dominated flow region have been recorded with a dual disc anemometer (DDA) and were obtained most of the free-jet particle velocities between 0.8 and 1.2 of the mean velocity [10].

Different sizes of abrasive particles have been considered to study erosion behavior of stainless steels using different characterization techniques: 3D-surface profilometer, scanning electron microscopy and atomic force microscopy [11]. The experimental setup parameters included: 401 of water volume, 0.5 vol\% of sand concentration in slurry, $480 \mathrm{~g}$ of used sand mass, different mean sand particle diameter $(50,80,150,350,450$, $700 \mu \mathrm{m}), 80 \mathrm{rpm}$ of stirrer speed, $43.5 \mathrm{rpm}$ of peristaltic pump speed, $30 \mathrm{~m} / \mathrm{s}$ of fluid flow velocity, $10 \mathrm{~min}$ of impingement duration, 4.7 bar of pulsation dampener pressure, $90^{\circ}$ of impingement angle and $12.7 \mathrm{~mm}$ of nozzle to target distance. The eroded samples are shown in section profile in Figure 4 in which the protruding island in the middle of the wear scar with "W" shape are gradually reduced in height as the mean sand particle size increases and is forming a wear scar with "U" shape cross-section. The variation or erosion depth with respect to particle size is shown in Figure 5 with an increase of wear scar proportional to the increasing of particle size because in each particle the impact energy increases. However, any increase in particle size after the strain hardening limit is reached would result in limited increase in the erosion depth [11].
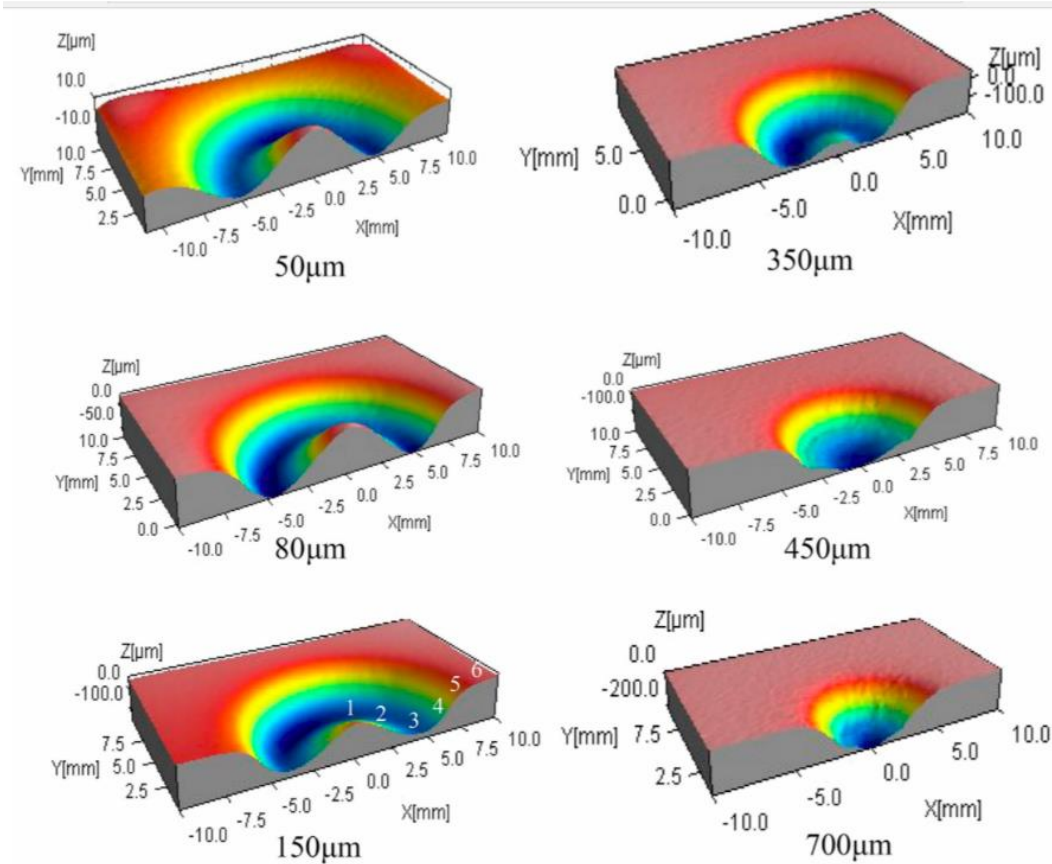

Fig. 4. 3D cross-section profile of eroded samples showing the transition from "W" to "U" shape [11].

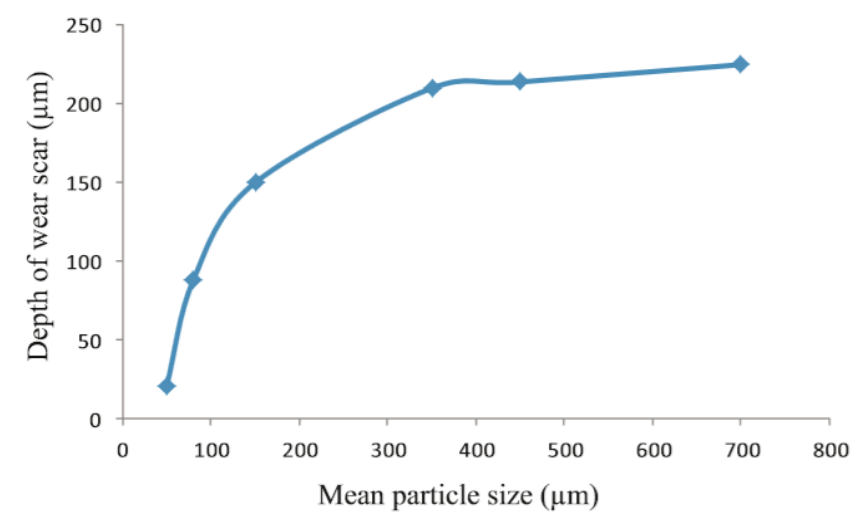

Fig. 5. Depth of erosion with respect to particle size [11].

The experimental results are recommended as a guide to predict erosion rate of SUS304 stainless steel when subjected to sand particles of different sizes. A mass loss per particle impact expression of erosion rate would be 
a better representation for investigating the mean particle sizes variation than a dimensionless erosion rate expression given by the sample weight loss per sand weight consumed.

Various traverse speed and standoff distances were considered for studying residual stresses and subsurface hardness of welded joints by peening with ultrasonic pulsed water jet at 20-60 MPa pressures. The influence of traverse speed, pressure and number of passes on the surface roughness of the austenitic stainless steel was analyzed with a contact-type profilometer. The measurements were conducted along the peening direction and the initial residual stress generated by the welding process was also measured for reference. At each pressure, increasing the traverse speed resulted in further improvement in the residual stress: at a pressure of $20 \mathrm{MPa}$ and a traverse speed of $v=2 \mathrm{~mm} / \mathrm{s}$. Lower compressive residual stresses were induced on samples surface at higher pressure. At a very low traverse speed of $0.25 \mathrm{~mm} / \mathrm{s}$, the highly stressed regions (with maximum principal stress recorded $145 \mathrm{MPa}$ ) on the material surface disintegrated during treatment. Authors recommend this traverse speed as a threshold for the treatment process, above which the samples can be treated without any disintegration [12].

\section{CONCLUSIONS}

AWJM will degrade the mechanical properties of composites and some methods have been developed for predicting the mechanical behavior to optimize machining quality. The impact of AWJ surface milling of composites materials on mechanical behavior is of interest to ascertain the usability of the process [3]. A promising new method for surface treatment of welded joints is given by PWJ. However, a detailed evaluation of the effect of the processing parameters on the residual stress and strengthening is still required [12].

An investigation of abrasive water jet cutting quality was conducted by an experimental method and recommended by the authors for prediction and control of the cutting parameters and quality with a specific developed software. The cutting walls quality was improved by tilting of the cutting head towards the traverse speed direction to the one-half of calculated declination angle. Declination angles obtained experimentally can describe the material cutting parameters and in perspective even for the determination of some material properties [8].

Nonconventional machining is preferred for it is less affected by the type of material as well as its hardness and strength. WED turning and AWJ turning were considered for machining of hybrid metal matrix composites. The roughness values of samples decreased while the rotational speed increased and those of WED turned were comparatively superior to AWJ ones [7].

The results obtained in a systematically theoretical analysis and numerical simulation of particle velocity in micro-AJM are recommended for further describing the AJM process which consist in reducing error in prediction of the material removal rate, machined profile, surface roughness and subsurface damage. The authors concluded that decreasing the hydraulic diameter of micro-nozzle $(<0.1 \mathrm{~mm})$ negatively affects air velocity even in case of smooth nozzle's wall [9].

\section{ACKNOWLEDGMENT}

This work was supported by a grant of the Romanian Ministery of research and Innovation, CCCDI-UEFISCDI, project number PN-III-P1-1.2-PCCDI-2017-0446/82PCCDI/2018 within PNCDI III.

\section{REFERENCES}

[1] Hlaváč, L.M., Hlaváčová, I.M., Arleo, F., Viganò, F., Annoni, M.P.G., Geryk, V., Shape distortion reduction method for abrasive water jet (AWJ) cutting, Precision Engineering, vol. 53, 2018, p. 194-202.

[2] Pervaiz, S., Kannan, S., Kishawy, H.A., An extensive review of the water consumption and cutting fluid based sustainability concerns in the metal cutting sector, Journal of Cleaner Production, vol. 197, 2018, p. 134153.

[3] Hejjaji, A., Zitoune, R., Toubal, L., Crouzeix, L., Collombet, F., Influence of controlled depth abrasive water jet milling on the fatigue behavior of carbon/epoxy composites, Composites Part A, vol. 121, 2019, p. 397-410. 
[4] Melentiev, R., Fang, F., Recent advances and challenges of abrasive jet machining, CIRP Journal of Manufacturing Science and technology, vol. 22, 2018, p. 1-20.

[5] Begic-Hajdarevic, D., Cekic, Ahmet, Mehmedovic, M., Djelmic, A., Experimental study on surface roughness in abrasive water jet cutting, Procedia Engineering, vol. 100, 2015, p. 394-399.

[6] Niranjan, C.A., Srinivas, S., Ramachandra, M., An experimental study on depth of cut of AZ91 Magnesium Alloy in abrasive water jet cutting, Materials Today: Proceedings, vol. 5, 2018, p. 2884-2890.

[7] Srivastava, A.K., Nag, A., Dixit, A.R., Scucka, J., Hloch, S., Klichová, D., Hlaváček, P., Tiwari, S., Hardness measurement of surfaces on hybrid metal matrix composite created by turning using an abrasive water jet and WED, Measurement, vol. 131, 2019, p. 628-639.

[8] Hlaváč, L.M., Hlaváčová, I.M., Gembalová, L., Kaličinský, J., Fabian, S., Měšt’ánek, J., Kmec, J., Mádr, V., Experimental method for the investigation of the abrasive water jet cutting quality, Journal of Materials Processing technology, vol. 209, 2009, p. 6190-6195.

[9] Ruslan, M., Fengzhou, F., Theoretical study on particle velocity in micro-abrasive jet machining, Powder Technology, vol. 344, 2019, p. 121-132.

[10] Haghbin, N., Khakpour, A., Schwartzentruber, J., Papini, M., Measurement of abrasive particle velocity and size distribution in high pressure abrasive slurry and water micro-jets using a modified dual disc anemometer, Journal of Materials Processing Technology, vol. 263, 2019, p. 164-175.

[11] Nguyen, Q.B., Nguyen, D.N., Murray, R., Ca, N.X., Lim, C.Y.H., Gupta, M., Nguyen, X.C., The role of abrasive particle size erosion characteristics of stainless steel, Engineering failure Analysis, vol. 97, 2019, p. 844-853.

[12] Srivastava, M., Hloch, S., Krejci, L., Chattopadhyaya, S., Residual stress and surface properties of stainlesssteel welded joints induced by ultrasonic pulsed water jet peening, Measurement, vol. 127, 2018, p. 453-462. 